\title{
Rentiers and Workers-Capitalists in a Non-Classical Model
}

\author{
Romar Correa \\ Department of Economics, University of Mumbai, Mumbai, India \\ Email: romarcorrea10@gmail.com
}

Received February 4, 2013; revised March 19, 2013; accepted March 29, 2013

Copyright (C) 2013 Romar Correa. This is an open access article distributed under the Creative Commons Attribution License, which permits unrestricted use, distribution, and reproduction in any medium, provided the original work is properly cited.

\begin{abstract}
We separate the "rentier" portion of the budget constraint of the representative agent from the "income-plus-distributed profits" segment. The former's wealth consists exclusively of returns on government bonds, the latter's wealth is wage income from working for firms plus the distributed profits of the latter. The non-neoclassical element is the non-imposition of the market-clearing assumption. The Barro-Ricardo theorem only applies to rentiers. The level of activity is shown to depend on the level of employment along with a set of parameters that capture the imperfect competition of the model.
\end{abstract}

Keywords: Financial Wealth; Competition; Public Works

\section{Introduction}

The financial crisis originating in the US of A was sufficient but not necessary to heighten protests against the representative agent that underlies the new classical (Keynesian) model that still holds sway over the profession. Franklin Fisher, Alan Kirman and many others have long established that the foundations of that fiction in pure theory are shaky. Still, while our model below can be regarded as part of the agent-based modeling response to the DSGE, we do not tamper with the elements of the maximand like discount rates and time horizons. Instead, we differentiate the interest-income and wage-cum-profits components in the right-hand side of the budget constraint of the representative agent. However, an important assumption we drop is that markets clear continuously.

The strategy is motivated by the increased financial layering that has begun to permeate economies beginning with the United States. The counterpart has been the constriction of the production of goods and services. Hein [1] has emphasised the increasing rate of return on bonds and the escalating potential for wealth- and debt-based consumption trajectories.

In the next section we work with a dynamic general equilibrium model with monetary-financial foundations. Two sharp results are discussed, one pertaining to the finance-government policy nexus, the second to the production of goods and services. A final section is an over- view of the theorems.

\section{The Institutional Framework and Results}

Outside of the United States, structural models with price-setting agents have long been staple fare. For instance, Benassy [2,3], has developed a framework that includes both price and quantity setting by households and firms. Agents are infinitely-lived households (rentiers and workers-capitalists), firms, and government. Households are indexed by $i \in[0,1]$, and firms by $j \in[0,1]$. As workers, households provide different qualities of labour. They set the corresponding wage, $W_{i}$. There is a homogenous consumption good (output) and differentiated intermediate goods indexed by $j \in[0,1]$. A one-to-one correspondence between intermediate good and firm $j$ exists. CES aggregators will be used in the noncompetitive account below.

The price of output is $P$. At the present time $t$, it is produced by competitive firms endowed with the following technology,

$$
Y_{t}=\left(\int_{0}^{1} Y_{j t}^{\theta} \mathrm{d} j\right)^{\theta}
$$

Firm $j$ produces its intermediate good using quantities of different types of labour $i, N_{i j t}$. It is characterized by a production function with the usual properties, 


$$
Y_{j t}=F\left(N_{j t}\right)
$$

where $N_{j t}$, a scalar index is deduced from the $N_{i j}$ s by an aggregator function

$$
N_{j t}=\left(\int_{0}^{1} N_{i j t}^{v} \mathrm{~d} i\right)^{1 / v}
$$

Firm $j$ seeks to maximize its profits

$$
\Pi_{j t}=\int_{s=t}^{\infty}\left(P_{j t} Y_{j t}-\int_{0}^{1} W_{i t} N_{i j t} \mathrm{~d} i\right) \mathrm{d} t
$$

The worker-household attempts to maximize her intertemporal utility function given by

$$
U_{i t}=\left(\int_{s=t}^{\infty} \mathrm{e}^{\beta(s-t)}\left(\log C_{i t}-V\left(N_{i t}\right) \mathrm{d} t\right)\right.
$$

where $V$ is a disutility function.

In time period $t$, household $i$ sets its wage and supplies a total quantity of labour

$$
N_{i t}=\int_{0}^{1} N_{i j t} \mathrm{~d} j
$$

In addition, all profits are distributed to households. So, worker i's share of profits is

$$
\Pi_{i t}=\int_{0}^{1} \Pi_{j t} \mathrm{~d} j
$$

From the above, worker $i$ consumes $C_{i t}$ and the surplus is "wealth", $\Omega_{i s+1}$, carried over to the next period, integrating over all time periods from the present,

$$
\int_{s=t}^{\infty} \Omega_{i s+1}=\int_{s=t}^{\infty}\left(W_{i s} N_{i s}+\Pi_{i s}-P_{s} C_{i s}\right)
$$

Taking the limit of the expression as $t \rightarrow \infty$, and imposing the transversality condition,

$$
W_{i t} N_{i t}+\Pi_{i t}=\int_{s=t}^{\infty}\left(P_{i s} C_{i s}\right) \mathrm{d} s
$$

Benassy (2002, 75-76) derives the following objective demand curves addressed to firm $j$ and household $i$ in period $t$.

$$
\begin{gathered}
Y_{j t}=\left(\frac{P_{j t}}{P_{t}}\right)^{-1 /(1-\theta)} Y \\
N_{i t}=\left(\frac{W_{i t}}{W_{t}}\right)^{-1 /(1-v)} \int_{0}^{1} F^{-1}\left(Y_{j t}\right) \mathrm{d} j
\end{gathered}
$$

where

$$
P_{t}=\left(\int_{0}^{1} P_{j t}^{-\theta /(1-\theta)} \mathrm{d} j\right)^{-\theta /(1-\theta)}
$$

and

$$
W_{t}=\left(\int_{0}^{1} W_{i t}^{-(1-v) / v}\right)^{-(1-v) / v}
$$

A worker-household will now choose its wage, labour supply, and consumption to maximize (5) subject to (8) and (10). The first-order conditions yield the intertemporal Euler condition for the worker,

$$
P_{s+1} C_{i s+1}=\beta P_{s} C_{i s}
$$

and

$$
\begin{aligned}
\frac{v}{P_{t} C_{i t}} & =\frac{V^{\prime}\left(N_{i t}\right)}{W_{i t}} \\
\frac{W_{i t}}{P_{t}} & =\theta F^{\prime}\left(N_{t}\right)
\end{aligned}
$$

We turn to the rentier. Her felicity function is identical to (5) but without the element representing the workleisure tradeoff. The rentier has positive holdings of government bonds, $B_{i t}$, inherited from the past. The current stock can also be negative which means that the rentier is borrowing from the government. The latter case might be regarded as a "bonds-in-advance" constraint without requiring the holder to spend the amount on current consumption. The absence of cash in what follows is justified by history. Central Banks rose from the pool of commercial banks and have recently begun to return to these origins. Bills of exchange slowly took on a fiat character. In the current period the rentier consumes and is taxed. Like the worker, the rentier consumes but, unlike the worker, only she pays tax $T_{i t}$. Rentier $i$ 's wealth, then, is

$$
\Omega_{i t}=B_{i t}
$$

The wealth transferred to the next period is

$$
\Omega_{i s+1}=\left(1+i_{s}\right) B_{i s}-P_{s} C_{i s}-P_{s} T_{i s}
$$

In a manner identical to the derivation of Equation (9) for the consumer, summing over all periods from $t$ to infinity and imposing the transversality condition, we get

$$
B_{i t}=\int_{s=t}^{\infty}\left(P_{s} C_{i s}+P_{s} T_{i s}\right) \mathrm{d} s
$$

The government budget constraint mirrors the budget constraint of the rentier,

$$
\Omega_{s+1}=\left(1+i_{s}\right) \Omega_{s}-P_{s} T_{s}
$$

Once more integrating forward and imposing a terminal-value condition, we derive

$$
B_{t}=\int_{s=t}^{\infty}\left(P_{s} T_{s}\right) \mathrm{d} s
$$


Combining (19) and (21), rentier consumption is

$$
\int_{s=t}^{\infty}\left(P_{s} C_{i s}\right) \mathrm{d} s=0
$$

The result can be summarized thus

Proposition 1. Ricardian equivalence is equivalent to "the euthanasia of the rentier".

In an essay "Economic Possibilities for our Grandchildren" written in 1930, Keynes looked forward to the "euthanasia of the rentier". His economic framework was built around decent work and employment and he had little sympathy for those who consumed without working. The equivalence result highlights the importance of "financial wealth taxation" rather than the undifferentiated lump-sum taxation of the standard model. Direct taxes are disapproved off anywhere as they allegedly load the work-leisure choice in favour of the latter. This microeconomic theorem does not apply to the rentier choice problem. Secondly, it is also irrelevant to the aggregate of choices in a macroeconomic model. Taxes on wealth (in this sense) and financial transactions continue to excite academic and popular debate. According to Moe [4], the result is consistent with consensus macroeconomics outside the mainstream. On the one hand, the monetary and the fiscal authorities are supposed to coordinate on policies to achieve full employment. Secondly, steeply progressive taxation might be returning to the models. The circular flow of goods and services and money requires distributed profits so that workers-consumers can spend their incomes and recycle them back to firms. High wages contribute to that end.

Aggregate consumption, then, is just Equation (9), the consumption of workers-capitalists,

$$
\int_{s=t}^{\infty} P_{s} C_{s}=W_{s} N_{s}+\Pi_{s}
$$

The intertemporal Euler condition for the rentier is more familiar,

$$
P_{s+1} C_{i s+1}=\beta\left(1+i_{s}\right) P_{s} C_{i s}
$$

Combining the two Euler conditions (14) and (22), we get the aggregate first-order condition

$$
P_{s+1} C_{s+1}=\left[\beta+\beta\left(1+i_{s}\right)\right] P_{s} C_{s}
$$

Alpha will turn out to be a multiplier where

$\alpha=\left[\beta+\left(1+i_{s}\right)\right]$.

The level of activity is given by the first-order conditions (15) and (16) along with $Y_{t}=F\left(N_{t}\right)$ and the aggregate budget constraints (19) and Euler Equation (24). The national income identity $P_{t} Y_{t}=W_{t} N_{t}+\Pi_{t}$ is used. In combination, this gives

$$
Y_{t}=\frac{1}{1-\alpha}\left(\theta v F^{\prime}\left(N_{t}\right) V^{\prime}\left(N_{t}\right)\right)
$$

In words,

Proposition 2. Output is independent of government.

The result can be viewed from opposite ends. On the one hand, with the coefficients theta and nu, it makes the case for vibrant markets. They are the "degrees of monopoly" held by firms and workers. As the elasticities approach unity, they approach the competitive outcome and increase output. Thus, freedom of entry and exit must be encouraged and monopolies, other than natural and public, discouraged. Trade unions, in the sense of blocking outsiders and fixing wages, are a thing of the past anyway. The model can be developed to include vigorous bargaining over productivity gains by small firms and groups of workers. At the same time, the letter $N$ in the numerator of the expression suggests Keynes rather than Keynesians. The latter are associated with $G$, government expenditure, which is conspicuously absent. Keynes wrote of public works and not fiscal policy. When output is at a less-than-full-employment level, the task of the government is to set out a schedule of projects that can employ able and willing hands at a dignified wage.

\section{Conclusions}

We develop a demand-determined model. The model dichotomises into a monetary-financial and a real sector. Over thirty years ago, Barro posed the question whether government bonds were net wealth and answered in the negative. The reason is that rational consumers would discount the present value of the wealth with the ownlifetime taxes they would have to pay on it. Therefore, present consumption equals present income. However, when present income is the return on government securities, the rentier vanishes. The Barro-Ricardo result can be interpreted as a balanced-budget case for confiscatory taxes on wealth. This does not mean that production and employment are outside government purview. Local governments can work through the intermediation of local banks to generate private-public participation in local projects.

\section{REFERENCES}

[1] E. Hein, "Finance-Dominated Capitalism and Redistribution of Income: A Kaleckian Perspective," Working Paper No. 746, Levy Economics Institute of Bard College, New York, 2013.

[2] J.-P. Bénassy, "The Macroeconomics of Imperfect Competition and Nonclearing Markets," The MIT Press, Cambridge, 2002.

[3] J.-P. Bénassy, "Money, Interest, and Policy," The MIT 
Press, Cambridge, 2007.

[4] T. G. Moe, "Marriner S. Eccles and the 1957 TreasuryFederal Reserve Accord: Lessons for Central Bank Inde- pendence," Working Paper No. 747, Levy Economics Institute of Bard College, New York, 2013. 